\title{
A Study on Comparison of Efficiency of Low-Density Polythene (LDPE) Degradation Under Aerobic and Anaerobic Conditions by Microorganisms Isolated from Soil
}

\author{
Ranjika Pallab Bhattacharya ${ }^{1 *}$, Hajra A.S. Gupta ${ }^{2}$
}

${ }^{* 1}$ Department of Biotechnology, Kishinchand Chellaram College, University of Mumbai, Mumbai, Maharashtra, India

${ }^{2}$ Department of Biotechnology, Kishinchand Chellaram College, University of Mumbai, Mumbai, Maharashtra, India

\section{Article Info}

Volume 8, Issue 2

Page Number: 326-334

\section{Publication Issue}

March-April-2021

\section{Article History}

Accepted: 01 April 2021

Published: 03 April 2021

\section{ABSTRACT}

Plastic has many desirable properties and thus, possesses several varied applications. This has led to a rise in its production and over the years, it has caused plastic pollution. Biodegradation is an affordable and more environment-friendly method compared to the other techniques currently available to eliminate plastic. The aim of this study was to isolate LDPE degrading microbes from soil samples that were collected from 4 different sources in Mumbai and compare their respective LDPE \% degradation rates. Isolation of potential plastic degraders was carried out on Bushnell Haas agar that was overlaid with LDPE strips. The final biodegradation rate was calculated by the weight loss reduction method after an incubation period of one month under aerobic and anaerobic conditions. For identification of the bacteria, gram staining and Matrix Assisted Laser Desorption/Ionization- Time of Flight (MALDI-TOF) Mass Spectroscopy were performed and several colony characteristics were studied. For identification of fungi, Potato Dextrose agar containing chloramphenicol was used as the selective media, and Lacto Phenol Cotton Blue staining was performed. Two facultative anaerobic bacterial isolates, Bacillus sp. and Staphylococcus cohnii ssp. urealyticus with LDPE degradation rates of $9.8 \%$ and $5.57 \%$ respectively, and a highly aerobic fungus, Aspergillus niger, with a degradation rate of $12.13 \%$ were found. Fungi showed the maximum rate of biodegradation. Bacillus species exhibited an almost double degradation capacity as compared to that of Staphylococcus species. To improve the biodegradation capacity, the optimum conditions for microbial growth and enzyme production can be assessed and these findings can be applied commercially on a larger scale.

Keywords: MALDI-TOF, plastic biodegradation, eco-friendly, Bacillus, Staphylococcus, Aspergillus. 


\section{INTRODUCTION}

Solid waste consists of unwanted materials generated due to human activities in housing, industrial, and commercial sectors. It has been found that solid waste comprises $10 \%$ of the total waste generated worldwide out of which $60-80 \%$ is plastic waste. These figures have skyrocketed over the years and reached an alarming rate of 230 million tonnes per year [1,2]. Central Pollution Control Board reports state that currently plastic usage in India stands at about 8 million tonnes per year out of which 5.7 million tonnes of waste is produced [3].

Plastic waste has escalated over the years due to a surge in its demand, sales, and consumption. This is mainly because it possesses many desirable properties such as it is quite strong, durable, lightweight, elastic, cheap to produce, resistant to corrosion, and has high thermal and electrical resistance, making it ideal for varied applications [4]. A major problem that arises due to plastic pollution is the ingestion of microplastics [5] by aquatic animals such as turtles, whales, seals that accidentally mistake them for food. This can cause blockage of their digestive systems and may lead to death, reduced levels of gastric enzymes and steroid hormones [6]. Marine creatures also get caught up in discarded plastic items like fishing nets [7]. Suspended plastic particles in the ocean may consist of highly toxic chemicals like PCBs, DDT, BPA, etc. [8] that undergo severe bio-amplification and can pose a direct risk to human health as well [9].

Since plastic is non-biodegradable or may potentially take several years to degrade [10], it continues to accumulate and harm the environment. Plastic pieces were found to interact with water and form hazardous chemicals which then seep underground and degrade the groundwater quality [11]. It also has a negative impact on the economy since it imposes additional costs of cleaning and disposal and affects tourism adversely [12].
Polyethylene (PE) is the most common type of solid waste produced. It is the result of addition or radical polymerization of ethylene molecules, in the presence of Ziegler Natta and Phillips catalysts [13].

The current methods used majorly to eliminate plastic include incineration and dumping in oceans or landfills. During incineration, toxins like dioxins, furans, heavy metals, and greenhouse gases are released into the atmosphere that contributes to severe air pollution [14]. Improper dumping of plastic wastes contaminates the environment and negatively affects the overall biodiversity [15]. These disposal methods have major limitations, making them highly ineffective. Thus, it is vital to switch to other alternatives.

One of them is oxidative degradation that occurs in the presence of oxygen free radicals. It is of 2 types: Photo-degradation and thermo-degradation [16]. Another method is biodegradation which is comparatively more affordable and an environmentfriendly method that makes it very widely accepted. However, its efficiency is moderate and it takes a longer period of time. This is a natural process wherein different types of microorganisms degrade complex organic materials, either aerobically or anaerobically. Aerobic biodegradation results in the production of water and carbon dioxide as endproducts whereas during anaerobic biodegradation, water, carbon dioxide, and methane are produced [17]. Some examples of microbes that exhibit biodegradation activity are bacteria (Psuedomonas, Streptococcus, Micrococcus, and Moraxella), fungi (Aspergillus), algae, and actinomycetes [18].

The primary objective of this study was to perform screening of soil samples that were collected from various locations in Mumbai city to isolate and identify certain microbes that exhibit significant LDPE biodegradation activity. 


\section{METHODS AND MATERIALS}

A. Sample Collection:

20-30 grams of soil samples $(4-5 \mathrm{~cm}$ from the soil surface) were collected from 4 different locations in Mumbai and stored in sterile, airtight containers.

\begin{tabular}{|c|c|}
\hline Soil Sample & Location \\
\hline Garden Soil & Lokhandwala \\
\hline Forest & Versova \\
\hline Dumping Ground & DN Nagar \\
\hline Mangrove Soil & Lokhandwala \\
\hline
\end{tabular}

TABLE 1: SOIL SAMPLE TYPE AND LOCATION

B. Enrichment and Isolation of Potential LDPE Degrading Microbes:

$20 \mathrm{~g}$ of each soil sample type was added separately to flasks containing sterile $200 \mathrm{~cm}^{3}$ Bushnell Haas broth [19] and $0.5 \mathrm{~g}$ of sterile $1 \mathrm{~cm}^{2} \mathrm{LDPE}$ strips, in order to prepare 4 sets. After incubation for 30 days at room temperature, a loopful of inoculum from all 4 sets was streaked separately on sterile Bushnell Haas agar plates that were coated with sterile $0.5{\mathrm{~g} 1 \mathrm{~cm}^{2} \mathrm{LDPE}}^{2}$ strips (Fig 1) [20]. These four plates were then incubated at $37^{\circ} \mathrm{C}$ for 5 days.

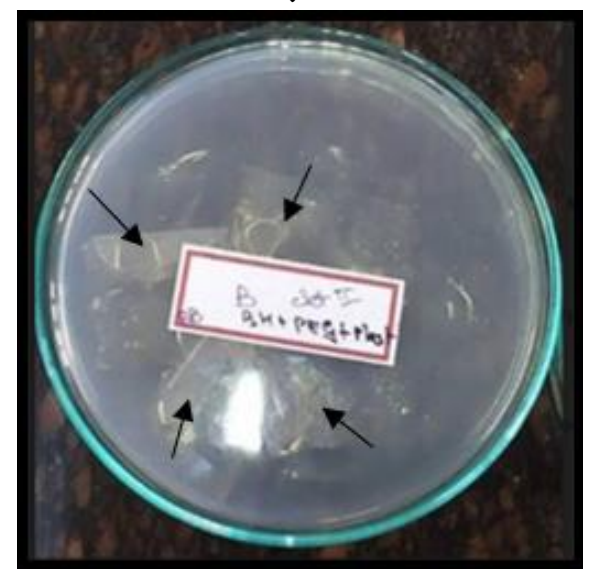

FIGURE 1 : LDPE STRIPS (INDICATED IN BLACK ARROWS) OVERLAID ONTO SOLIDIFIED BUSHNELL HAAS AGAR IN PETRI PLATE
C. Obtaining Pure Culture and Checking Growth Under Aerobic and Anaerobic Conditions:

Pure colonies that exhibited rapid growth on the LDPE strips were selected. Each colony was separately streaked on a sterile Bushnell Haas agar plate that was overlaid with sterile $0.5{\mathrm{~g} 1 \mathrm{~cm}^{2} \mathrm{LDPE}}^{2}$ strips under aseptic conditions and incubated at $37^{\circ} \mathrm{C}$ for 5 days under aerobic conditions. The pure colonies were sub-cultured on sterile Nutrient agar slants and stored at $4^{\circ} \mathrm{C}$ for further studies.

The growth of these pure isolates was further checked under anaerobic conditions. Each isolate was streaked on a sterile Bushnell Haas agar plate that was overlaid

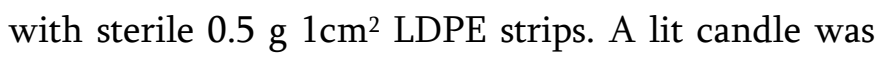
placed in a glass jar and then it was tightly shut. Petroleum jelly was applied on all the edges in order to ensure that the jar was completely air-tight and no oxygen could enter inside. The above-prepared plates were then placed into this airtight, anaerobic glass jar which was saturated with carbon dioxide for a period of 5 days [21]. It was vital to leave this set-up undisturbed during the incubation time of 5 days.

\section{Bulk Growth of Pure Isolates:}

A loopful of each pure isolate was inoculated in sterile $100 \mathrm{~cm} 3$ nutrient broth [22]. This was incubated at $37^{\circ} \mathrm{C}$ for 10 days.

E. Determination of LDPE Degradation Rates of Isolates:

The bulk growth of each pure isolate (approximately $0.25 \mathrm{~g}$ ) was added to a conical flask containing sterile $100 \mathrm{~cm} 3$ Bushnell Haas broth and sterile $0.5 \mathrm{~g} 1 \mathrm{~cm}^{2}$ LDPE strips. The flasks containing aerobic cultures were incubated at $37^{\circ} \mathrm{C}$ for 30 days and the flasks containing facultative anaerobic/ anaerobic cultures were placed in an airtight anaerobic glass jar for 30 days. A control flask was simultaneously maintained in both cases. After 30 days, the LDPE strips were 
extracted from the broth using forceps, washed thoroughly with tap water first and then distilled water, cleaned using 70\% alcohol, and finally dried on filter papers. It was vital to ensure that culture was not stuck to the LDPE strips as this could add to the final weight.

The final weight of the strips was recorded and the LDPE degradation rates, i.e., \% weight loss for the respective isolates was calculated by the given formula [19]:

\section{LDPE \% degradation rate}

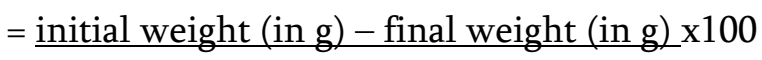
initial weight

\section{F. Identification of the isolates:}

The bacterial isolates were identified based on gram staining, their colony characteristics, and MALDITOF MS results [23]. Fungal isolates were identified by the colour and morphology of the aerial mycelia on $2 \%$ Potato dextrose agar (with chloramphenicol) as a selective media [24], followed by LPCB staining with reference from keys by Raper and Fennell [25].

\section{RESULTS AND DISCUSSION}

A. Enrichment and Isolation of Potential LDPE Degrading Microbes:

The enrichment step was important for the microbes to recognize LDPE as the new carbon source. A period of 30 days was chosen for this as it gave the microbes adequate time to get acclimatized to the new environment by increasing the production of extra-cellular enzymes that help in cleaving the large, high molecular weight polymers into smaller fragments that are further biomineralized into endproducts. In most cases, these end-products are carbon dioxide, water, and methane [18]. They are harmless and can easily be used up by the microbes as a form of energy source. Similar work was carried out by Asmita et al wherein Bushnell Haas broth was selected as the enrichment medium and the enrichment process was carried out for 30 days [19]. Bushnell Haas media contains all the essential nutrients required for microbial growth; however, it does not contain any carbon source. LDPE in the form of strips was chosen as the sole hydrocarbon source for the microbes.

After incubation of all the plates, it was seen that only the plates belonging to sets 2,3 , and 4 showed the presence of distinct microbial colonies on the LDPE strips. This indicated that soil samples belonging to the forest, dumping ground, and mangrove, respectively, contained certain microbes that were able to utilize LDPE as the sole hydrocarbon source and so they were able to grow on the strips. These colonies were selected and studied further.

\section{B. Checking Growth of Pure Isolates Under Aerobic} and Anaerobic conditions:

3 pure colonies that were seen to be rapidly growing on the LDPE films on the Bushnell Haas media were selected. This kind of media preparation is similar to Das et al wherein 3\% LDPE powder was added to the growth media [26]. In this study, instead of adding LDPE powder to the media, LDPE strips were overlaid onto the solidified growth media. The oxygen requirements of the colonies were further determined. To prepare the anaerobic gas chamber, the same method was followed as stated by Saha et al. A lit candle was placed in an air-tight glass chamber in order to completely saturate it with carbon dioxide. This method was chosen since it is more economical as compared to other commercially available equipment that require reagents like bicarbonate solution [21]. The 2 bacterial isolates were found to be facultative anaerobic while the only fungal isolate was highly aerobic. 
C. Determination of LDPE degradation rates of isolates:

Sets 1 and 2 (Fig 2) contained bacterial isolates 1 and 2, respectively, and set 3 (Fig 3) contained isolate 3 which was a fungus. The initial and final weights of LDPE strips were recorded for all 3 isolates (Table 2) and the LDPE biodegradation rates were calculated by weight reduction method and compared with each other (Graph 1). This work can be compared to Das et al wherein weight-loss method was used as well. This was found to be the most convenient and simplest method compared to all the other possible methods such as SEM and FTIR analyses [26]. During the biodegradation process of 30 days, the flasks were left undisturbed which confirms the fact that the microbes were only able to grow by utilizing LDPE.

It was determined that the fungal isolate exhibited the greatest LDPE biodegradation rate of $12.13 \%$. On the other hand, bacterial isolates 1 and 2 had degradation rates of $5.57 \%$ and $9.8 \%$, respectively. This result is in accordance with existing literature that states fungi have a much higher biodegradation capacity as compared to bacteria. This is because fungi have the ability to attach to polymer surfaces with the help of extracellular polysaccharides and form biofilms. Biofilms aid in decreasing the hydrophobicity of LDPE so that the extracellular enzymes can conduct fragmentation more easily. Fungi also produce thin, long hyphae that allow them to penetrate further and reach longer distances in the search for nutrients. This helps them to survive longer than bacteria under harsh conditions, for example, nutrient starvation $[26,27]$.

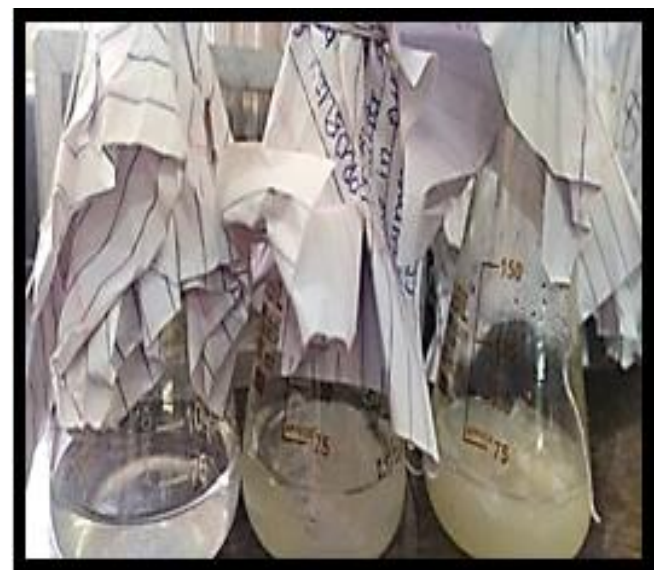

FIGURE 2: CONTROL, SET 1, SET 2 (FROM LEFT TO RIGHT)

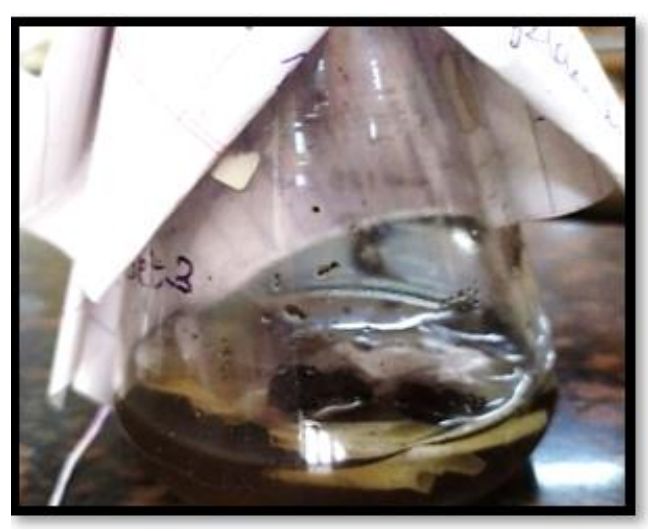

FIGURE 3: SET 3

\begin{tabular}{|c|c|c|c|}
\hline Isolate & $\begin{array}{c}\text { Initial } \\
\mathbf{w t}(\mathrm{g})\end{array}$ & $\begin{array}{c}\text { Final } \\
\mathbf{w t}(\mathrm{g})\end{array}$ & $\begin{array}{c}\text { LDPE \% } \\
\text { biodegradation } \\
\text { rate }\end{array}$ \\
\hline 1 & 0.503 & 0.475 & 5.57 \\
\hline 2 & 0.510 & 0.460 & 9.8 \\
\hline 3 & 0.445 & 0.391 & 12.13 \\
\hline Control & 0.520 & 0.520 & 0 \\
\hline
\end{tabular}

TABLE 2: LDPE \% BIODEGRADATION RATES 


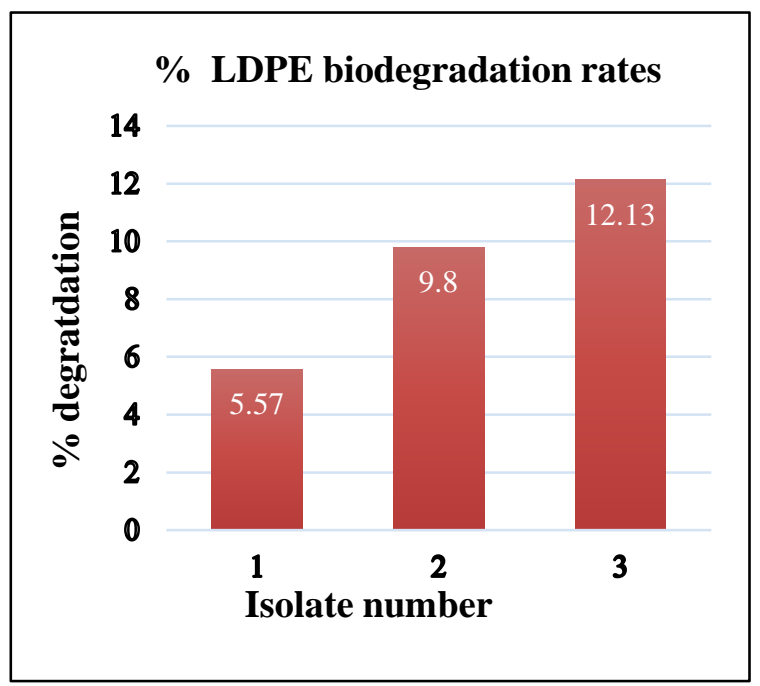

GRAPH 1: COMPARISON OF LDPE \% BIODEGRADATION RATES OF ISOLATES

D. Identification of Bacterial Isolates:

On performing gram staining and observing under the microscope, it was seen that isolate 1 had purple cocci, in singles or clusters. Isolate 2 had purple rods, in singles or pairs. Various colony characteristics of both isolates were studied (Table 3). MALDI-TOF MS was performed. This technique allows the identification of a wide spectrum of proteins which aids in classifying the isolates at a species level. This was found to be rapid, cost-effective and more sensitive towards the identification of anaerobes as compared to other techniques [28]. Since both the bacterial isolates in this study were determined to be facultative anaerobic, this technique was chosen.

Isolate 1 was Staphylococcus cohnii ssp. urealyticus (Fig 4) and isolate 2 was Bacillus subtillis/ amyloliquefaciens/ vallismortis (Fig 5). The final MALDI-TOF MS results obtained for isolate 1 (Fig 6) and isolate 2 (Fig 7) are shown below.

\begin{tabular}{|c|c|c|}
\hline & Isolate 1 & Isolate 2 \\
\hline Size & $1 \mathrm{~mm}$ & $3 \mathrm{~mm}$ \\
\hline Shape & circular & circular \\
\hline Colour & white & white \\
\hline Margin & entire & entire \\
\hline
\end{tabular}

\begin{tabular}{|c|c|c|}
\hline Surface & $\begin{array}{c}\text { smooth and } \\
\text { shiny }\end{array}$ & smooth \\
\hline Elevation & raised & raised \\
\hline Consistency & butyrous & butyrous \\
\hline Opacity & translucent & opaque \\
\hline Pigmentation & absent & absent \\
\hline Gram nature & + & + \\
\hline Morphology & cocci & bacilli \\
\hline Arrangement & $\begin{array}{c}\text { Singles or in } \\
\text { pairs }\end{array}$ & $\begin{array}{c}\text { Singles or } \\
\text { in pairs }\end{array}$ \\
\hline Motility & Non-motile & motile \\
\hline
\end{tabular}

TABLE 3: COLONY CHARACTERISTICS OF BACTERIAL ISOLATES

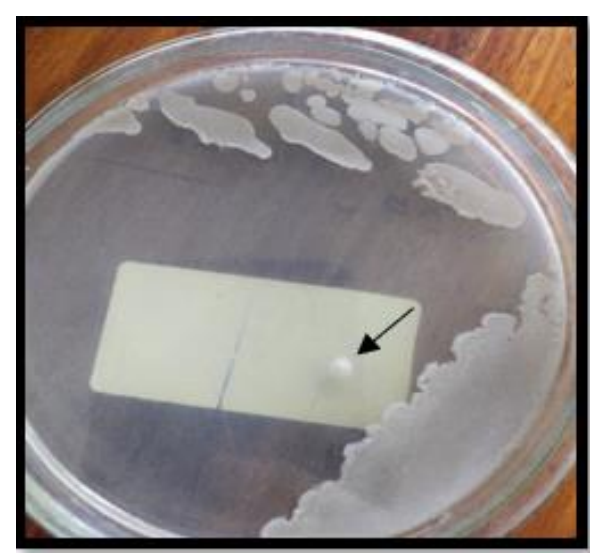

FIGURE 4: PURE STAPHYLOCOCCUS SPECIES COLONY (INDICATED BY BLACK ARROW) ON NUTRIENT AGAR SELECTED FOR MALDI-TOF MS ANALYSIS (ISOLATE 1)

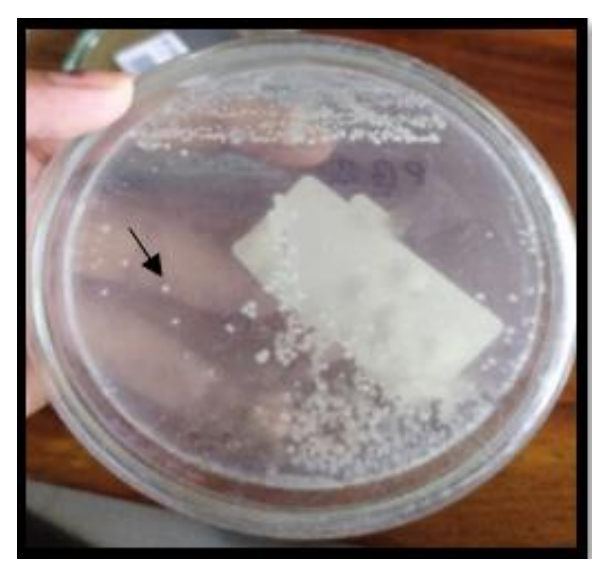

FIGURE 5: PURE BACILLUS SPECIES COLONY (INDICATED BY BLACK ARROW) ON NUTRIENT 
AGAR SELECTED FOR MALDI-TOF MS ANALYSIS (ISOLATE 2)

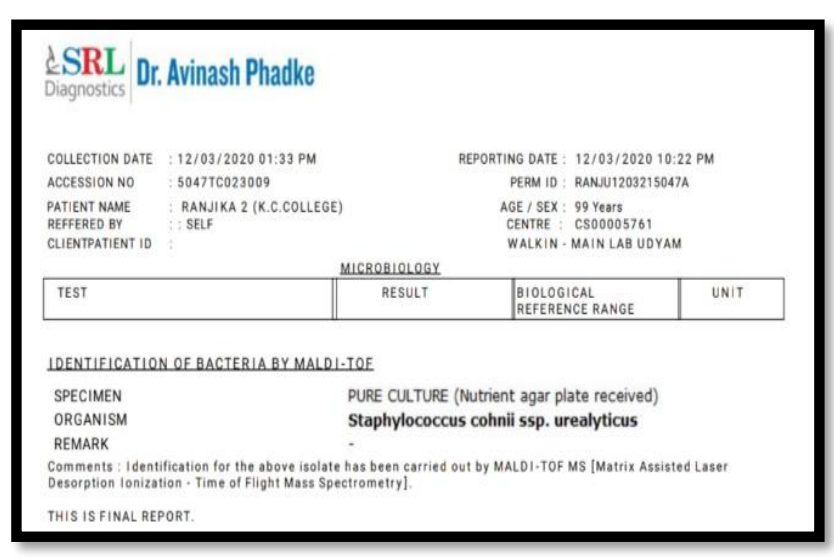

FIGURE 6: MALDI-TOF MS REPORT FOR ISOLATE-1 (STAPHYLOCOCCUS COHNIISSP. UREALYTICUS)

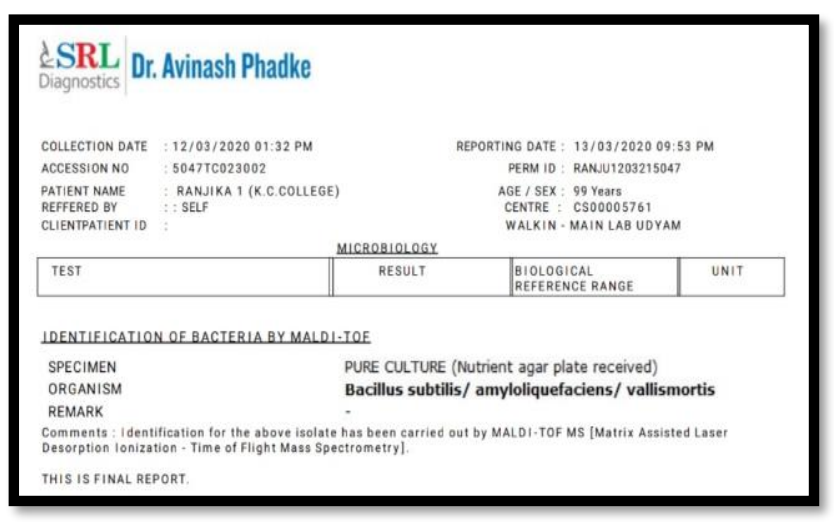

FIGURE 7: MALDI-TOF MS REPORT FOR ISOLATE-2 (BACILLUS SUBTILLIS/ AMYLOAQUEFACIENS/ VALLISMORTIS)

E. Identification of Fungal Isolates:

The fungal isolate was cultured and purified on selective media ( $2 \%$ potato dextrose agar that contained chloramphenicol) that was prepared in a way similar to Shafique et al [29]. It was seen that the colonies were initially colourless but after 2-3 days, they became brownish-black (Fig 6). Further, Lactophenol Cotton Blue (LPCB) staining was carried out. On observing the fungal isolate under 40X, conidial heads, long conidiophores, and septate hyphae could clearly be seen (Fig 7). Metulae and phialides were seen to be covering the globular vesicles. Spores produced from conidial heads were seen as well which is a distinguishing feature of Aspergillus niger. These findings were in line with what was seen in previous studies [30]. To confirm the presence of $A$. niger, keys by Raper and Fennel were followed [25].

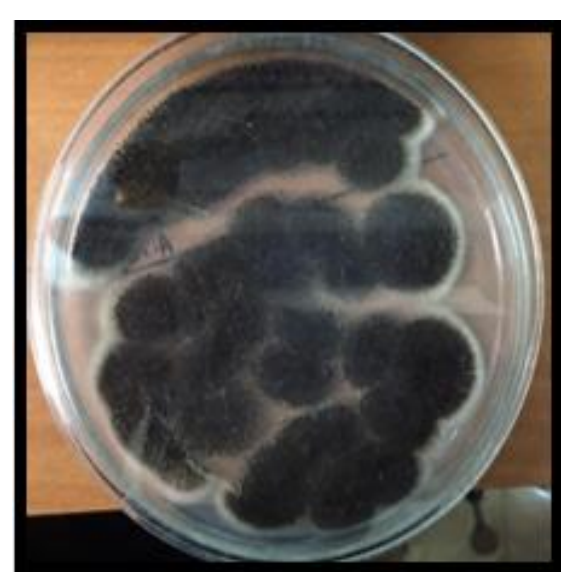

FIGURE 8: ASPERGILLUS NIGER ON POTATO DEXTROSE AGAR

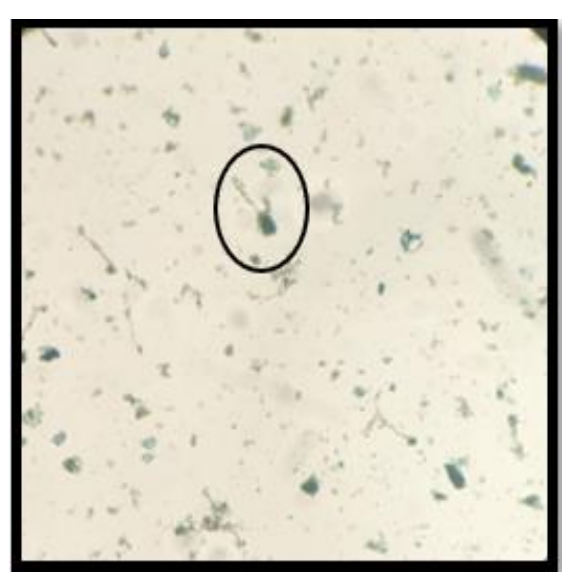

FIGURE 9: LACTO PHENOL COTTON BLUE (LPCB) STAINING OF ASPERGILLUS NIGER SHOWING CONIDIAL HEADS AND SEPTATE HYPHAE (ENCIRCLED) 


\section{CONCLUSION}

Biodegradation of plastics is a more suitable and widely accepted alternative to the other methods currently used as it is relatively more cost-effective and eco-friendlier. In this study, many microbes isolated from soil were screened for their ability to utilize LDPE as the sole hydrocarbon source in the presence of Bushnell Haas media. Two facultative anaerobic bacterial isolates, Staphylococcus cohnii ssp. urealyticus and Bacillus subtillis/ amyloliquefaciens/ vallismortis, and one highly aerobic fungal isolate, Aspergillus niger, were found to exhibit significant LDPE percentage biodegradation activity of 5.57\%, $9.8 \%$ and $12.13 \%$, respectively. Fungi were seen to have the maximum biodegradation activity.

This study compared biodegradation rates of only LDPE. Toxicity testing for the end-products of biodegradation was not carried out. Since MALDITOF MS analysis was done, the bacterial isolates were determined accurately only up to species level. In the future, 16S rRNA sequencing can be done for more accurate determination. The biodegradation activity of these isolates on other types of plastics could be studied as well. Metagenomics studies could also be carried out to identify the primary genes responsible for the biodegradation activity.

\section{ACKNOWLEDGEMENT}

We would like to thank Dr. Sejal Rathod, Coordinator of the Department of Biotechnology at K.C. College, for providing us access to the laboratory and the required facilities. We are very grateful for all the support and kindness we have received from the teachers and the lab assistants of the Biotechnology Department at K.C. College. We would like to express our gratitude towards SRL Diagnostics for MALDITOF MS facility. Lastly, we are extremely thankful to the Jigyaasa Science Honors Program of K.C. College for providing us with this wonderful opportunity.

\section{REFERENCES}

[1]. Heap, B. (2009). Was there a scientific consensus about risks associated with the rising accumulation, deposition and interaction of multiple forms of plastics and leached additives in the environment? Preface. Philosophical Transactions of the Royal Society of London. Series B, Biological Sciences, 364(1526), 1971-1971.

[2]. Mudgal, S., Lyons, L., Bain, J., Dias, D., Faninger, T., Johansson, L., ... \& Bowyer, C. (2011). Plastic waste in the environment-Revised final report for European Commission DG environment. Bio Intelligence Service, 2047-062.

[3]. Rathi, S. (2006). Alternative approaches for better municipal solid waste management in Mumbai, India. Waste management, 26(10), 1192-1200.

[4]. Thompson, R. C., \& Moore, C. J. (2009). FS vomSaal and SH Swan. Philos. Trans. R. Soc. London, Ser. B, 364, 2153-2166.

[5]. Sighicelli, M., Pietrelli, L., Lecce, F., Iannilli, V., Falconieri, M., Coscia, L., ... \& Zampetti, G. (2018). Microplastic pollution in the surface waters of Italian Subalpine Lakes. Environmental Pollution, 236, 645-651.

[6]. Wilcox, C., Van Sebille, E., \& Hardesty, B. D. (2015). Threat of plastic pollution to seabirds is global, pervasive, and increasing. Proceedings of the National Academy of Sciences, 112(38), 1189911904.

[7]. Jeftic, L., Sheavly, S., Adler, E., \& Meith, N. (2009). Marine litter: a global challenge.

[8]. Gregory, M. R. (2009). Environmental implications of plastic debris in marine settings-entanglement, ingestion, smothering, hangers-on, hitch-hiking and alien invasions. Philosophical Transactions of the Royal Society B: Biological Sciences, 364(1526), 2013-2025.

[9]. Hirai, H., Takada, H., Ogata, Y., Yamashita, R., Mizukawa, K., Saha, M., ... \& Ward, M. W. (2011). Organic micropollutants in marine plastics debris from the open ocean and remote and urban beaches. Marine pollution bulletin, 62(8), 1683-1692.

[10]. Elordi, G., Lopez, G., Aguado, R., Olazar, M., \& Bilbao, J. (2007). Catalytic pyrolysis of high density polyethylene on a HZSM-5 zeolite catalyst in a 
conical spouted bed reactor. International Journal of Chemical Reactor Engineering, 5(1).

[11]. Barnes, D. K., Galgani, F., Thompson, R. C., \& Barlaz, M. (2009). Accumulation and fragmentation of plastic debris in global environments. Philosophical transactions of the royal society B: biological sciences, 364(1526), 1985-1998.

[12]. Re, V. (2019). Shedding light on the invisible: addressing the potential for groundwater contamination by plastic microfibers. Hydrogeology Journal, 27(7), 2719-2727.

[13]. Ronca, S. (2017). Polyethylene. In Brydson's plastics materials (pp. 247-278). Butterworth-Heinemann.

[14]. Verma, R., Vinoda, K. S., Papireddy, M., \& Gowda, A. N. S. (2016). Toxic pollutants from plastic waste-a review. Procedia Environmental Sciences, 35, 701708.

[15]. Chae, Y., \& An, Y. J. (2018). Current research trends on plastic pollution and ecological impacts on the soil ecosystem: A review. Environmental pollution, 240, 387-395.

[16]. Hawkins, W. L. (1964). Thermal and oxidative degradation of polymers. Polymer Engineering \& Science, 4(3), 187-192.

[17]. Siracusa, V. (2019). Microbial degradation of synthetic biopolymers waste. Polymers, 11(6), 1066.

[18]. Shah, A. A., Hasan, F., Hameed, A., \& Ahmed, S. (2008). Biological degradation of plastics: a comprehensive review. Biotechnology advances, 26(3), 246-265.

[19]. Asmita K, Shubhamsingh T, Tejashree S (2015) Isolation of plastic degrading micro-organisms from soil samples collected at various locations in Mumbai, India. Int Res J Envir Sci, 4:77-85.

[20]. Optimum Conditions for LDPE Strips Biodegradation by Local Bacterial Isolates. (2015). Journal of International Environmental Application and Science, 10(4), 399-407.

[21]. Saha, U. S., Misra, R., Tiwari, D., \& Prasad, K. N. (2016). A cost-effective anaerobic culture method \& its comparison with a standard method. The Indian journal of medical research, 144(4), 611.

[22]. Difco \& BBL. (2009). Nutrient agar. Difco \& BBL Manual of Microbial Cell Culture, (July), 2-3. Retrieved
http://www.neogen.com/Acumedia/pdf/ProdInfo/71 45_PI.pdf

[23]. Wieser, A., Schneider, L., Jung, J., \& Schubert, S. (2012). MALDI-TOF MS in microbiological diagnostics-identification of microorganisms and beyond (mini review). Applied microbiology and biotechnology, 93(3), 965-974.

[24]. Aryal, S. (2018). Potato Dextrose Agar (PDA)Principle, Uses, Composition, Procedure and Colony Characteristics.

[25]. Raper, Kenneth Bryan, and Dorothy I. Fennell. "The genus Aspergillus." The genus Aspergillus. (1965).

[26]. Das, M. P., \& Kumar, S. (2014). Microbial deterioration of low density polyethylene by Aspergillus and Fusarium sp. Int J Chem Tech Res, 6(1), 299-305.

[27]. Orr, I. G., Hadar, Y., \& Sivan, A. (2004). Colonization, biofilm formation and biodegradation of polyethylene by a strain of Rhodococcus ruber. Applied microbiology and biotechnology, 65(1), 97104.

[28]. Croxatto, A., Prod'hom, G., \& Greub, G. (2012). Applications of MALDI-TOF mass spectrometry in clinical diagnostic microbiology. FEMS microbiology reviews, 36(2), 380-407.

[29]. Shafique, S., Bajwa, R., \& Shafique, S. (2009). Screening of Aspergillus niger and A. flavus strains for extra cellular alpha-amylase activity. Pak. J. Bot, 41(2), 897-905.

[30]. Shamly, V., Kali, A., Srirangaraj, S., \& Umadevi, S. (2014). Comparison of microscopic morphology of fungi using lactophenol cotton blue (LPCB), iodine glycerol and congo red formaldehyde staining. Journal of clinical and diagnostic research: JCDR, 8(7), DL01.

\section{Cite this article as:}

Ranjika Pallab Bhattacharya, Hajra A.S. Gupta, "A Study on Comparison of Efficiency of Low-Density Polythene (LDPE) Degradation Under Aerobic and Anaerobic Conditions by Microorganisms Isolated From Soil", International Journal of Scientific Research in Science and Technology (IJSRST), Online ISSN : 2395-602X, Print ISSN : 2395-6011, Volume 8 Issue 2, pp. 326-334, March-April 2021. Available at doi $\quad$ : https://doi.org/10.32628/IJSRST218249 Journal URL : https://ijsrst.com/IJSRST218249 